\title{
Editorial
}

Pathobiology

\section{Investigations of Pathologists as a Key to Understanding Coronavirus Disease 2019}

\author{
Thomas Menter Alexandar Tzankov \\ Pathology, Institute of Medical Genetics and Pathology, University Hospital Basel, University of Basel, Basel, \\ Switzerland
}

For more than half a year, the world is grappling with coronavirus disease 2019 (COVID-19) caused by severe acute respiratory syndrome-coronavirus 2 (SARS$\mathrm{CoV}-2$ ). A long-time neglected part of the work of surgical pathologists, autopsy has thus again shifted into the spotlight as an indispensable tool to analyse new diseases systematically and comprehensively [1].

Tissue-based analysis of samples collected at autopsies of COVID-19 patients has contributed significantly to understanding this novel disease [2,3], outlining its main adverse features, and thus helping to focus on potential life-saving therapeutic approaches, for example, improving the rheological properties of the blood or endothelial fitness in face of the microthromboses detected at autopsies (Fig. 1) [4]. Autopsy could also help to define highrisk patient cohorts and contribute to answering the question whether patients tested positive for SARSCoV-2 and/or displaying symptoms of COVID-19 were dying with or of the disease $[2,5]$. COVID-19 has led to an unprecedented flood of publications and theories related to the disease leading to controversies and uncertainties regarding many aspects, ranging from the occurrence of endothelialitis $[6,7]$ and the question of virally induced acute kidney injury [8] or encephalitis [9] to the

karger@karger.com

(C) 2020 S. Karger AG, Basel

www.karger.com/pat

Karger! visualisation of SARS-CoV-2 by electron microscopy [7]. To resolve these open issues, comprehensive and indepth studies and larger meta-analyses will be needed, to which currently Pathobiology is contributing a dedicated fascicle. In this special issue of Pathobiology, a wide spectrum of research performed by surgical pathologists from Europe and the USA has been collected in an effort to get a better understanding of the pathophysiology of COVID-19 and help to tackle the issues mentioned above.

A large autopsy study of 32 cases by Salvatore et al. [10] from the New York, one of the epicentres of the pandemic, showed the diversity of pathologic findings: besides diffuse alveolar damage, this cohort confirmed the increased frequency thromboembolisms in multiple organ systems. Furthermore, thanks to the diligent work-up of the cases, distinct histopathological patterns in lymph nodes and the liver were observed. Analysis of the patient collective reinforces the link between comorbid disease and lethal COVID-19. A smaller case series from Poland by Chmielik et al. [11] shows similar variegated pathology findings of COVID-19 and, importantly, that previously healthy individuals can succumb to this disease. The latter observation particularly highlights the importance to perform autopsies and collect material for fur- 


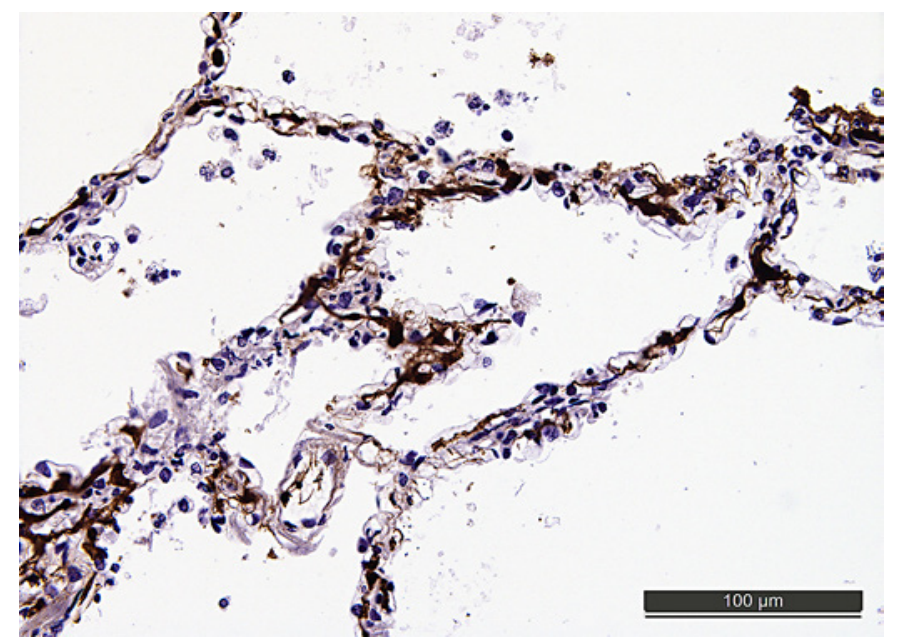

Fig. 1. Lung parenchyma of a COVID-19 patient collected at autopsy showing extensive microthrombi in alveolar capillaries (fibrin immunohistochemistry, $\times 320$ ).

ther in-depth investigations such as whole-genome sequencing which would identify specific risk factors in younger individuals without obvious risk factors.

Thanks to these post-mortem analyses, we now acknowledge that COVID-19 is a systemic angiocentric disease (Fig. 2) primarily involving the lungs [3] with an additional major impact on coagulation and other organ functions. Wool and Miller [12] review the current state of knowledge regarding COVID-19 and alterations of platelets and coagulation. They show a positive correlation between elevated D-dimers and mortality and a prominence of thrombembolisms and microvascular thrombotic disorders in COVID-19 patients. However, they also raise the question whether coagulopathies seen in COVID-19 should rather be seen in the context of generalized inflammatory response and not as being a unique specific feature. Indeed, a report of an autopsy series focusing on liver pathology by Schmit et al. [13] from Belgium showed that liver findings are primarily to be interpreted as secondary changes due to hypoxia or drug toxicity, in line with neuropathological data on COVID-19, which is likely a correlate of critical illness-related encephalopathy and thus not a result of virally induced damage [9].

A case report by Showers et al. [14] on a woman suffering from COVID-19 and concomitant complementmediated coagulopathy and transient antiphospholipid antibody positivity points, along with other recent obser-

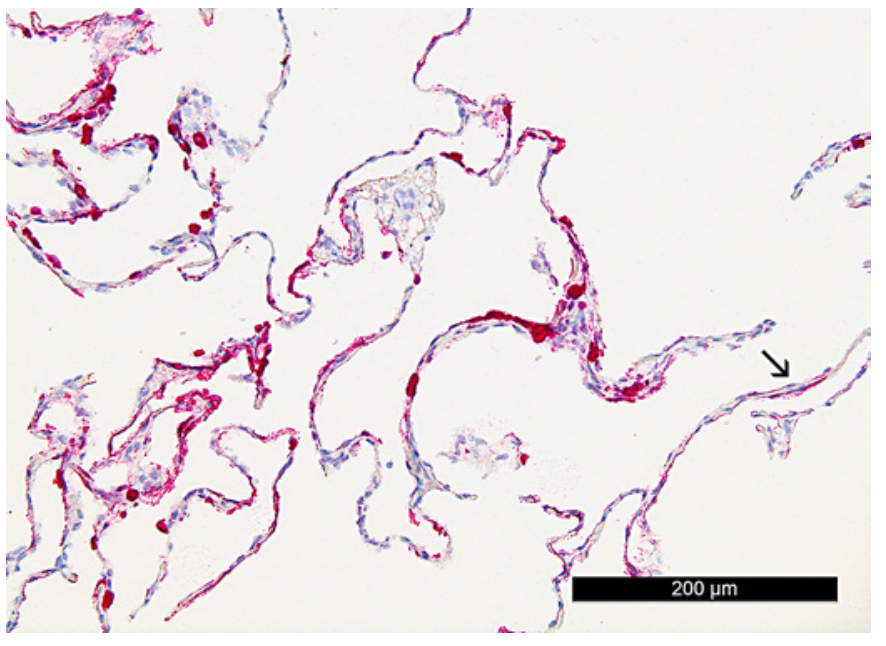

Fig. 2. Lung parenchyma of a COVID-19 patient showing presence of SARS-CoV-2 in pneumocytes, macrophages and endothelial cells, the latter seen by smooth parallel lines of red chromogen deposits in the alveolar walls (arrow) (SARS-CoV-2 nucleocapsidantigen immunohistochemistry, $\times 200)$.

vations $[15,16]$, towards a possible link between COVID-19 and the generation of such antibodies with subsequent thromboembolic events. Importantly, this may explain the fact that despite adequate thromboprophylaxis, COVID-19 is still associated with a high rate of venous and arterial thromboembolic events.

Two contributions from Switzerland include a characterization of the morphology of placentas of women infected with SARS-CoV-2 and a retrospective analysis of autopsies performed before the outbreak of COVID-19 aiming to elucidate whether SARS-CoV-2 had reached Basel before the country's first case in late February $2020[17,18]$. The placenta study revealed that in gravid women with manifest COVID-19, there are signs of lymphohistiocytic inflammation as well as presence of SARS-CoV-2 in the decidua and in decidualized endometrium, another piece of evidence which points to pregnant women as a risk group for serious disease [19]. On the other hand, asymptomatic women tested SARSCoV-2 positively before or at the time of birth only showed mild placental changes. Haslbauer et al. [18] found no evidence of SARS-CoV-2-infection before the officially declared first case in Switzerland by retrospectively analysing collected pulmonary tissues of patients who have died between 2019 and February 2020 with symptoms resembling COVID-19 or displaying histopathological changes commonly observable in lethal COVID-19. 
In order to perform autopsies of COVID-19 patients and to analyse potentially highly contagious tissue, a special equipment is required in pathology laboratories. Loibner et al. [20] give an overview on biosafety requirements according to different international standards and provide insights into the design and technical equipment of the biosafety level-3 laboratory at the Medical University of Graz that is specifically designed for autopsies involving highly pathogenic agents or other unknown pathogens.

The economic impact of the current pandemic has reached pathology laboratories. De Pelsemaeker et al. [21] were able to show in a retrospective analysis that the overall amount of specimens in both surgical pathology and cytopathology significantly decreased in Belgium. This was especially related to a reduction of samples related to cancer screening. This diagnostic delay in diagnoses of malignancies points towards another potential severe consequence of COVID-19, in particular with patients suffering from highly aggressive tumours [22-24].

Taken together, we hope the reader of this special issue of Pathobiology can benefit from the collected high-quality contributions bearing new insights in pathologies encountered in COVID-19 as well as getting information on the impact of the pandemic on global healthcare chal- lenges. The close collaboration of medical specialists in the learning process around COVID-19 and other unknown disease is mandatory. No single expertise will be able to "solve" the riddle. A virus is nothing without the host and its reactions. So the understanding of any viral disease will go along with the fine analysis of the hosts' tissue and immunological reaction. We have to foster the interdisciplinary work-up of COVID with the histopathological work-up as an incontournable starting point.

\section{Conflict of Interest Statement}

The authors declare to have no competing interests.

\section{Funding Sources}

This work is supported by the Botnar Research Centre for Child Health, BRCCH.

\section{Author Contributions}

Both T.M. and A.T. designed and wrote the editorial. A.T. provided the figures.

\section{References}

1 Calabrese F, Pezzuto F, Fortarezza F, Hofman P, Kern I, Panizo A, et al. Pulmonary pathology and COVID-19: lessons from autopsy. The experience of European Pulmonary Pathologists. Virchows Arch. 2020;477(3):35972.

2 Menter T, Haslbauer JD, Nienhold R, Savic S, Hopfer H, Deigendesch N, et al. Postmortem examination of COVID-19 patients reveals diffuse alveolar damage with severe capillary congestion and variegated findings in lungs and other organs suggesting vascular dysfunction. Histopathology. 2020;77(2):198209.

3 Ackermann M, Verleden SE, Kuehnel M, Haverich A, Welte T, Laenger F, et al. Pulmonary vascular endothelialitis, thrombosis, and angiogenesis in Covid-19. N Engl J Med. 2020;383(2):120-8.

4 Zhang XJ, Qin JJ, Cheng X, Shen L, Zhao YC, Yuan Y, et al. In-hospital use of statins is associated with a reduced risk of mortality among individuals with COVID-19. Cell Metab. 2020;32(2):176-e4.

5 Tzankov A, Jonigk D. Unlocking the lockdown of science and demystifying COVID-19: how autopsies contribute to our understanding of a deadly pandemic. Virchows Arch. 2020;477(3):331-3.
6 Varga Z, Flammer AJ, Steiger P, Haberecker M, Andermatt R, Zinkernagel AS, et al. Endothelial cell infection and endotheliitis in COVID-19. Lancet. 2020;395(10234):1417-8.

7 Goldsmith CS, Miller SE, Martines RB, Bullock HA, Zaki SR. Electron microscopy of SARS-CoV-2: a challenging task. Lancet. 2020;395(10238):e99.

8 Delsante M, Rossi GM, Gandolfini I, Bagnasco SM, Rosenberg AZ. Kidney involvement in COVID-19: need for better definitions. J Am Soc Nephrol. 2020;31(9):2224-5.

9 Deigendesch N, Sironi L, Kutza M, Wischnewski S, Fuchs V, Hench J, et al. Correlates of critical illness-related encephalopathy predominate postmortem COVID-19 neuropathology. Acta Neuropathol. 2020;140(4):5836.

10 Elsoukkary SS, Mostyka M, Dillard A, Berman DR, Ma LX, Chadburn A, et al. Autopsy findings in 32 patients with COVID-19: a single-institution experience. Pathobiology. 2020:1-13.

11 Chmielik E, Jazowiecka-Rakus J, Dyduch G, Nasierowska-Guttmejer A, Michalowski L, Sochanik A, et al. COVID-19 autopsies: a case series from Poland. Pathobiology. 2020:1-10.
12 Wool GD, Miller JL. The impact of COVID-19 disease on platelets and coagulation. Pathobiology. 2020:1-13.

13 Schmit G, Lelotte J, Vanhaebost J, Horsmans $\mathrm{Y}$, Van Bockstal M, Baldin P. The Liver in COVID-19-related death: protagonist or innocent bystander? Pathobiology. 2020:1-7.

14 Showers CR, Nuovo GJ, Lakhanpal A, Siegel $\mathrm{CH}$, Aizer J, Elreda L, et al. A covid-19 patient with complement-mediated coagulopathy and severe thrombosis. Pathobiology. 2020:1-9.

15 Mathian A, Mahevas M, Rohmer J, Roumier M, Cohen-Aubart F, Amador-Borrero B, et al. Clinical course of coronavirus disease 2019 (COVID-19) in a series of 17 patients with systemic lupus erythematosus under longterm treatment with hydroxychloroquine. Ann Rheum Dis. 2020;79(6):837-9.

16 Amezcua-Guerra LM, Rojas-Velasco G, Brianza-Padilla $M$, Vazquez-Rangel A, Marquez-Velasco R, Baranda-Tovar F, et al. Presence of antiphospholipid antibodies in COVID-19: case series study. Ann Rheum Dis. 2020.

17 Menter T, Mertz KD, Jiang S, Chen H, Monod C, Tzankov A, et al. Placental pathology findings during and after SARS-CoV-2 infection: features of villitis and malperfusion. Pathobiology. 2020:1-9. 
18 Haslbauer JD, Perrina V, Matter M, Dellas A, Mihatsch MJ, Tzankov A. Retrospective postmortem SARS-CoV-2 RT-PCR of autopsies with COVID-19-suggestive Pathology pupports the absence of lethal community spread in Basel, Switzerland, before February 2020. Pathobiology. 2020:1-11.

19 Akhtar H, Patel C, Abuelgasim E, Harky A. COVID-19 (SARS-CoV-2) infection in pregnancy: a systematic review. Gynecol Obstet Invest. 2020;85(4):295-306.

20 Loibner M, Langner C, Regitnig P, Gorkiewicz $\mathrm{G}$, Zatloukal K. Biosafety requirements for au- topsies of patients with Covid-19: example of a BSL-3 autopsy facility designed for highly pathogenic agents. Pathobiology. 2020 Dec;1-9.

21 de Pelsemaeker MC, Guiot Y, Vanderveken J, Galant C, Van Bockstal MR. The impact of the COVID-19 pandemic and the Associated Belgian Governmental Measures on Cancer Screening, Surgical Pathology and Cytopathology. Pathobiology. 2020:1-10.

22 Ricci F, Fania L, Paradisi A, Di Lella G, Pallotta S, Sobrino L, et al. Delayed melanoma diagnosis in the COVID-19 era: increased breslow thickness in primary melanomas seen after the COVID-19 lockdown. J Eur Acad Dermatol Venereol. 2020.

23 Chiaravalli S, Ferrari A, Sironi G, Gattuso G, Bergamaschi L, Puma N, et al. A collateral effect of the COVID-19 pandemic: delayed diagnosis in pediatric solid tumors. Pediatr Blood Cancer. 2020;67(10):e28640.

24 Parasole R, Stellato P, Conter V, De Matteo A, D'Amato L, Colombini A, et al. Collateral effects of COVID-19 pandemic in pediatric hematooncology: fatalities caused by diagnostic delay. Pediatr Blood Cancer. 2020;67(8): e28482. 